\title{
La identidad cultural: una perspectiva filosófica
}

\author{
Raimundo Prado R. \\ Departamento Académico de Filosofía
}

No hay país más diverso, más múltiple en variedad terrena y humana; todos los grados de calor y color, de amor y odio, de urdimbres y sutilezas, de símbolos utilizados e inspiradores. No por gusto, como diría la gente llamada común, se formaron aquí Pachacamac y Pachacutec, Huamán Poma, Cieza y el Inca Garcilaso, Tupac Amaru y Vallejo, Mariátegui y Eguren, la fiesta de Qoyllur Riti y la del Señor de los Milagros; los yungas de la costa y de la sierra, la agricultura a los 4,000 metros; patos que hablan en lagos de altura donde todos los insectos de Europa se ahogarían; picaflores que lleguen hasta el sol para beberle su fuego y llamear sobre las flores del mundo. Imitar desde aquí a alguien resulta algo escandaloso. En técnica nos superarán y dominarán, no sabemos hasta qué tiempos, pero en arte podemos ya obligarlos a que aprendan de nosotros y lo podemos bacer incluso sint mevemos de aquí mismo.

\section{"Jorge Puccinelli Converso"}

Palabras de José María Arguedas en el acto de entrega del premio "Inca Garcilaso de la Vega" (Lima, octubre de 1968).

El presente ensayo tiene como finalidad esencial el análisis filosófico inicial de la idea de "identidad cultural".

Nuestra perspectiva filosófica no consiste en la elaboración de una "teoría" sino en la elucidación contextual del tema que nos compromete. Siguiendo esta estrategia metodológica, los tópicos brevemente analizados son los siguientes: primero, se muestra la diversidad de componentes de la idea de "identidad" como los aspectos descriptivo, proscriptivo y programático. En segundo lugar, hay una suerte de determinación de un conjunto de elementos para una definición de la identidad como realidad, 
como ideología y como utopía. Finalmente, se analiza críticamente la correlación entre la identidad y la globalización culturales. El trabajo termina con la propuesta de una identidad cultural peruana deseable, según nuestra perspectiva valorativa.

\section{Distinciones necesarias}

Nuestra perspectiva sobre la problemática de la "identidad cultural peruana" es eminentemente filosófica. La elucidación de sus supuestos, generalmente implícitos, y la distinción de sus aspectos es nuestra tarea fundamental. Evidentemente, nuestras reflexiones tienen como base los estudios históricos-sociales y políticos-culturales existentes en nuestros medios bibliográficos'.

Una primera cuestión que nos interpela es la extrema ambigüedad y complejidad del problema. Un cuadro sintomático de esta situación es la diversidad de usos de la palabra "identidad". Desde un punto de vista conceptual, como se estableció en un seminario interdisciplinario dirigido por Lévi-Strauss, el campo que abarca esta idea oscila entre "una singularidad desconectada" (cerrada) y "una unidad globalizante poco respetuosa de las diferencias" (homogeneizadora) ${ }^{2}$.

Esta diversidad dejusos, cencaferentes sentides y alcances, de la idea de "identidad" nos motiya a preguntarios si esposible formular una definición o, por lo menos, señalar ciertos elementos comunes (elementos definitorios) para construir el concepto de identidad. Reiteramos que, para realizar esta operación, debemos tener presente la ostensible diversidad de sus usos lingüísticos; así, se suele hablar de identidades étnica, regional, nacional, estamental, clasista, religiosa, moral, política, ideológica, utópica, etc. El cuadro se complica si atendemos al mayor o menor grado de intensidad o nitidez de sus configuraciones típicas o peculiares; de este modo es dable hablar de un identidad en un sentido "débil" o en un sentido "fuerte". Asimismo, es distinguible por el nivel de su autognosis, lo que parafraseando a Hegel-Marx podemos llamarlas como "identidad en sî? (cuando no se tiene o se tiene una débil conciencia de su situación identitaria) e

1 Documentos importantes, consistentes en testimonios de parte, se encuentran en el libro ¿Quiénes somos?, cuyos editores son Rodrigo Montoya y Luis Enrique López, Lima, Mosca Azul, 1988.

2 Citado en francés por Elena Aybar Ray: Identidad y resistencia cultural en las obras de José María Arguedas, Lima, PUCP, 1992, pp. 54-55. 
“identidad para si" (se da o se logra en una comunidad con clara conciencia de su situación, historicidad y posibilidades).

Desde otro punto de vista analítico, podemó destacar tres momentos o niveles en la identidad cultural: a) en primer lugar, presenta un nivel o sentido descriptivo (contiene aspectos descriptivos de situaciones objetivamente configuradas), b) un aspecto prospectivo (apunta o señala a posibilidades o tendencias objetivas, las que no necesariamente son deseables) y c) un nivel o sentido prescriptivo-programático (propuesta político-cultural de una identidad ideal o deseable).

En suma, una identidad implica una "situación" y, al mismo tiempo, una asunción de "posición"; contiene componentes de sentimiento, valoración y conocimiento. Siempre se encuentra en proceso y es resultado de un complejo y conflictivo proceso histórico.

\section{Para una definición de la "identidad cultural"}

¿Tiene sentido hablar de la "identidad cultural" en general teniéndose en cuenta que en la realidad sólo existen identidades diversas y concretas? Nosotros sostenemos que la "identidad cultural en general" es una abstracción y, en cuanto tal, puedel set ună abstacción cortectasy ser la base de una construcción conceptual En ptras palabras of el concepto de "identidad cultural" en general sólo se articulan los elementos comunes esenciales y reiterativos de las diversas formas concretas de identidad.

Así, no obstante la borrosidad de sus contornos, en todas las formas específicas de identidad cultural hay zonas o focos relativamente claros en los que son distinguibles las características comunes siguientes:

a) Una relación, individual y colectiva, de pertenencia al grupo y cierto de grado de conciencia o de reconocimiento de esta relación.

b) Una relación de identificación y de valoración positiva, en algún nivel, de esta pertenencia por los miembros del grupo.

c) La asimilación y revaloración de las raíces, y de las tradiciones, del grupo como condición de la formación de su personalidad histórica y del desarrollo de su capacidad creativa.

d) Una configuración peculiar de la que se tiene cierta conciencia 
(conciencia identitaria) y reconocible desde fuera y por otros.

e) La posesión de cierta capacidad creativa a partir de sus propias disposiciones o fuentes internas.

f) La participación en una historia común y de un espacio geográfico determinado.

g) La posesión de una determinada capacidad de apertura y de asimilación recíproca en relación con otros grupos. Como decía Franz Fanon, "la identidad cultural no es cerrazón" ${ }^{3}$. Incluso, las identidades fuertes como las étnicas, que por razones de resistencia cultural se autobloquean, no pueden ser definitiva o absolutamente cerradas.

\section{La dialéctica de la identidad cultural: encuentros de culturas y categorias de su inteligibilidad.}

En la historia intelectual de los pueblos colonizados, historia de la formación de identidades, Franz Fanon ${ }^{4}$ encuentra tres etapas claramente perfiladas. En una primera fase, según nuestro escritor, el intelectual colonizado asimila en forma integral la cultura del invasor y prueba de este modo su capacidad o condición humana. El segundo momento es el de la reinmersión: es el momento do la memoria y del vómito. En este periodo de reacción, el intelectual colonizado se da cuenta de su relación enajenada con el pueblo y se contenta con recordardahistoriapre-celonial. En el fondo de la memoria redescubre viejos episodios $₫$ deyendas, y los revalora. Es el periodo de malestar, de experiencia de la muerte y de la náusea. Se vomita, pero ya, por debajo, se prepara la risa.

El tercer periodo es el de la lucha. El intelectual colonizado, tras haber intentado perderse en el pueblo o con el pueblo, va por el contrario a sacudirlo. Se transforma en el que despierta al pueblo. Su literatura se transforma en literatura de combate, literatura revolucionaria, literatura nacional.

En José Carlos Mariátegui, también encontramos un esquema parecido de periodización de la literartura en el Perú. Según el Amauta, "una teoría moderna -literaria, no sociológica-sobre el proceso normal de la literatura de un pueblo distingue en él tres pertodos: un periodo colonial, un periodo

3 Franz Fanon, Los condenados de la tierra. México, Fondo de Cultura Económica, 1977, p. 226.

4 Ibid., pp. 202-203. 
comopolita, un periodo nacional. Durante el primer periodo de un pueblo, literariamente, no es sino una colonia, una dependencia de otro. Durante el segundo periodo, asimila simultáneamente elementos de diversas literaturas extranjeras. En el tercero, alcanzan una expresión bien modulada su propia personalidad y su propio sentimiento"s.

Nosotros juzgamos que los esquemas históricos propuestos, tanto de Fanon como de Mariátegui, pueden ser criterios útiles para la explicación y comprensión de la historia dialéctica de constitución de la identidad cultural nacional. Lamentablemente, no tenemos el tiempo necesario para hacer un estudio comparativo y, sobre todo, epistemológico de este problema. Pero, a continuación, no dejaremos de señalar las categorías más importantes que posibilitan la inteligibilidad de las identidades culturales. Una tentativa inicial de invertario de cstas categorías, nos permitiría descubrir algunos formas específicas como las siguientes: la aculturación, la transculturación, la resistencia, la asimilación y tradueción recíprocas, etc.

La aculturación consiste en la pérdida o sustitución de la cultura propia por otra. Generalemente se da en un contexto de relaciones de dominación o de alienación culturales y que puede variar desde un proceso de "extirpación" o de destrucción hasta el abandono de la cultura propia por la imposición de supuestos valores superieres y universales đe etra-cultura.

La transculturación consiste en la apertura y apropiación de lo extraño (generalmente dominante), la que implica, al mismo tiempo, la revaloración y la transformación de la propia identidad cultural. Según Arguedas, se trata de la estrategia de los dominados para no perder sus propias raíces en la constitución de una nueva identidad.

La resistencia cultural -la que generalmente ocurre como defensa de la propia identidad-consiste, en su forma típica, en una suerte de encerramiento. Históricamente, sin duda, presenta diferentes modalidades que no analizaremos en este momento.

La asimilación y la traducción recíprocas sólo pueden darse entre culturas bien constituidas y que presenten más o menos el mismo grado de

5. José Carlos Mariátegui, 7 ensayos..., 1957, p. 207. 
desarrollo histórico. Pues, pensamos, como hacía notar también Antonio Gramsci, que la traducción recíproca o simétrica requiere como condición esta base del mismo nivel de desarrollo cultural.

\section{La identidad como realidad, ideología y utopía}

En forma purificada, ya que la identidad conocreta es siempre un proceso histórico complejo y combinado, son distinguibles la identidad como realidad, como ideología y como utopía.

La identidad como realidad consiste en una configuración histórica y objetivamente determinable. El conjunto de características que conforman la identidad son reconocibles desde fuera. Justamente, el trabajo científico, de un antropólogo, por ejemplo, consiste básicamente en la determinación y explicación de estos elementos constitutivos objetivos de una identidad.

La identidad como ideología consisteen la presentación discursiva deformada y unilateral de la realidad identitaria. En nuestra historia, por ejemplo, encontramos ideologizaciones típicas de nuestra precaria identidad nacional. Así, para nuestros escritores como Riva-Agüero y Alejandro Deustua, el componente indígena es la parte exótica y extirpable; sólola parte hispánica es valiosa. Naturalmente, esta posición valorativa se funda en ünå visión unilateral ỳ deforrnada de das razas en el Perú; no se quiere fundar nuestra identidad enel reconocimiento de lapluralidad cultural realmente existente y de sus potencialiđades de asimilación y de creación. Otro caso interesante es la ideología del "mestizaje" que aparentemente puede reconocer diversas confluencias culturales pero subrepticiamente sobrevalora un componente determinado, por ejemplo el hispánico costeño como en el "criollismo". En suma, la ideología, como señala nuestro historiador Basadre, es siempre una perspectiva parcial con pretensiones de totalidad; siempre mistifica o invierte la realidad.

La identidad como utopía es una construcción ideal, realizable o no según sus condiciones de posibilidad; así, por ejemplo, tenemos la esperanza mariateguiana de la "peruanización" del Perú.

\section{Identidad y globalización}

Indudablemente, los graves problemas de la identidad cultural en nuestro país y en el continente amerindio, se han dado desde la conquista 108 
ibérica y lusitana. Desde entonces estamos viviendo el proceso de occidentalización, un proceso homogeneizador que ha originado dolorosos problemas de identidad cultural. Juzgamos que este proceso debe ser estudiado en sus momentos cualitativamente diferentes y con la más sobria objetividad. Por razones metodológicas, cuyos supuestos explicitamos ahora, pensamos que debe comenzarse con el análisis crítico de su forma actual: el fenómeno de la "globalización". En esta oportunidad, a continuación, nos contentaremos con señalar una gran falacia de la ideología globalizadora.

La ideología globalizadora (expresión discursiva del capitalismo neoliberal) se presenta como la portadora de la más alta racionalidad, como la defensora y difusora de los valores de libertad e igualdad, como la que por su naturaleza responde a los intereses de toda la humanidad. Sostiene que el sistema económico-mundial está regulado por el mercado en el cual el individuo-consumidor es "soberano"; rechaza y exige la eliminación de toda suerte de planificación social. Todas estas ideas, curiosamente, ya forman parte de las creencias a todo nivel.

La globalización realmente existente o en proceso de realización es al revés de lo que presenta la ideología: es destructora de valiosas identidades culturales, posee una racionalidad instrumental subalterna (defiende intereses egoístas). Es encubridơra dẻ das verdaderas fuerzas ysprácticas reguladoras de la sociedad capitalista: la fuerza dominante de los oligopolios (la "soberanía del mercado libre" es apariencial) y la estricta planificación enajenante de los países deudores por las instituciones internacionales a su servicio. Habla de la soberanía del individuo en el momento en que se atan las relaciones de dependencia más cosificantes.

En síntesis, la globalización efectiva se caracteriza por ser asimétrica, socialmente irracional, excluyente, homogeneizadora y destructora. No se trata de un proceso de integración con asimilaciones recíprocas.

\section{La identidad cultural peruana: una propuesta}

Como afirman muy bien los más calificados analistas de la sociedad peruana, no cabe hablar de "una identidad cultural peruana". Salvo en términos de posibilidades o de tesis programáticas. Nuestra realidad es pluricultural, multilingüe y pluri-racial. Sin duda, hay embrionarias 
configuraciones y una historia englobante y estas condiciones posibilitan hablar, hoy, de unas incipiente identidad o "peruanidad". Justasmente, esta situación, como una suerte de respuesta esperanzada, nos motiva a explicitar ciertos valores que animan nuestra propuesta de una identidad deseable:

En primer lugar, un proceso de creación de la identidad cultural peruana debe tener como su polo valorativo el ensanchamiento o el enriquecimiento de la calidad humana en todas sus direcciones.

Segundo, este proceso de enriquecimiento tiene como condición necesaria una actitud de apertura que posibilite la apropiación autónoma (sin coacciones) de toda creación humana.

Tercero, el proceso de crecimiento integral del hombre peruano no es posible sin la revaloración y reapropiación de las raíces indígenas o del componente andino.

Cuarto, la identidad de nuestra propuesta no es misoneísta. Es una identidad abierta a la creación y a lo auténticamente nuevo.

Quinto, la identidad de nuestra esperanza es una identidad con memoria, pero sin mistificaciones de nuestro pasado y porvenir.

Apreciación final

El examen inichial de la problemấtica dela "identidad cultural peruana", nos permitg bacer las siguientesapreciaciones:

1. Hay frecuentes confusiones sobre la problemática de la identidad cultural por no distinguir los niveles real, ideológico y utópico.

2. No cabe hablar con sentido de "identidad cultural peruana" si no es en el nivel conceptual y programático.

3. La globalización constituye la forma más irracional de destrucción de la embrionaria identidad nacional.

4. No hay identidad cultural peruana posible sin la reapropiación y revaloración del componente indígena y andino. 